\title{
Obrigações e deveres na tradução de Ibsen
}

\author{
Leonardo Pinto Silva ${ }^{1}$
}

"Traduir és cuinar un plat estranger amb ingredients de la terra" Marta Pera Cucurell, in facebook.com/las1001 traducciones

Os textos dramáticos de Henrik Ibsen (1828-1906), um dos pilares do teatro como o conhecemos hoje, tiveram surpreendente boa acolhida nos palcos cariocas até o início do século passado. Aqui, público e crítica travaram um contato precoce com "Uma casa de bonecas" já em 1899, vinte anos depois da estreia no país de origem, e a esta montagem sucederam diversas outras.

Para isso, o gênio criativo do maior dramaturgo norueguês foi determinante, não há dúvida, mas um certo diplomata russo (!) também contribuiu. Tradutor da maioria dos escritos de Ibsen para o francês, seu interlocutor frequente e reconhecido divulgador do seu legado, o conde Moritz Prozor trocou o rigoroso inverno de Moscou pelo clima ameno da aprazível Petrópolis, na serra fluminense. O Brasil da época, com seu pendor pelo galicismo, tinha um tesouro ao alcance da mão.

Ibsen aproximou a rigidez do drama clássico às nuanças do teatro contemporâneo. Aboliu a sequência cronológica linear em nome da simultaneidade e trouxe o conflito psicológico das personagens para o centro da trama, na arguta

1 Leonardo Pinto Silva é formado em comunicação social pela UFC e tem mestrado em administração de empresas pela Ebap/FGV-RJ. Aprendeu o idioma na Noruega, onde estudou. Em 1998, traduziu seu primeiro título do norueguês, "Na trilha de Adão", a autobiografia do explorador Thor Heyerdahl, mas só recentemente intensificou sua atividade como tradutor literário também do inglês. Já traduziu mais de vinte títulos do norueguês, entre eles "O mundo de Sofia”, de Jostein Gaarder. Vive em São Paulo. 


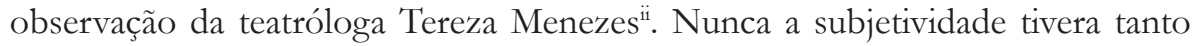
destaque no palco, de onde jamais arredou pé desde então.

Curiosamente, porém, pouquíssimas das suas 38 peças teatrais (e nenhum da sua centena de poemas ou da sua vasta produção não ficcional) estão, até onde se sabe, disponíveis entre nós, ao menos em traduções diretaiiii. Na sua percuciente tese de mestrado nesta USP (2007) ${ }^{\text {iv }}$, Jane Pessoa da Silva cita "Inimigo do povo" em tradução direta de James Colby, possivelmente no início do século XX. Em 2006, o professor Karl Erik Schøllhammer, da PUC-RJ, trouxe-nos "Casa de boneca" para uma encenação alusiva ao centenário de morte do autor"; e, uma década antes, em parceria com Fátima Saadi, "Quando nós os mortos despertarmos", "John Gabriel Borkman" e "O pequeno Eyolf”, estas últimas publicadas pela Editora 34 e ora esgotadas.

Sabendo-se que a Noruega será homenageada na Feira de Frankfurt de 2019, era oportuno propor a alguma casa editorial suprir essa lacuna com títulos representativos do teatro ibseniano. Especialmente a produção tardia de Ibsen, enfocada menos no simbolismo que no realismo, reveste-se de uma atualidade aguda e urge ser redescoberta pelo público brasileiro nesta travessia entre um passado que nos persegue e um futuro que vislumbramos e se delineava promissor, mas não aconteceu. Este é, não por acaso, o Zeitgeist que plasmou a obra de Henrik Ibsen.

Uma empreitada de fôlego, sem dúvida. Pela prosa sutil e multifacetada, por se tratar de manuscritos de mais de cem anos, pelas adaptações, paráfrases e eventuais textos de apoio necessários para contextualizar a sociedade norueguesa do final do século XIX para o leitor brasileiro contemporâneo. Como manter acesa, numa prosa à altura, a aura de clássicos que já passaram pela pena de Clarice Lispector, Barbara Heliodora e Millôr Fernandes e foram encarnados por Beatriz Segall e Paulo Autran? Trata-se de alta literatura para ser fruída como tal, sim, mas também de uma criação que visava o palco, regida pelo discurso direto, fluente e sem afetações. Deve-se mencionar aqui a exímia habilidade do autor enquanto realizador teatral, donde a profusão de marcações, interjeições, frases de efeito, trocadilhos incontornáveis e demais artifícios para dar maior impacto ao texto encenado.

Assenhorar-se desta tarefa já seria desmesura suficiente, ainda mais para alguém cuja formação como tradutor é mais empírica que teórica - e cuja formação em dramaturgia é nenhuma, aliás. Mas há também o fato de Ibsen ter se expressado em riksmaal, a forma arcaica de norueguês desenvolvida a partir de 1879 e anterior à reforma gráfica de 1907, que resultou no bokmål contemporâneo. O leitor destes Cadernos deverá saber que todo norueguês nativo é bilíngue no próprio idioma. $\mathrm{O}$ 
nynorsk ("novo norueguês") é, a despeito do nome, um híbrido de dialetos ainda mais antigos que a "língua dos livros": o bokmål evoluiu do dano-norueguês de grafia quase idêntica, deixando pelo caminho a prosódia gutural, paradas glotais, fonemas surdos e demais excentricidades do trava-línguas que ainda hoje se pratica na Dinamarca ${ }^{\text {vi }}$. O Ibsen original está num “idioma que já não existe” esperando ganhar voz no brasiliansk, como querem na Noruega, um "idioma que existe sem ser", tal a distância entre fala, escrita e norma culta no português brasileiro. Descobrir a "norma oculta" era o grande abismo a transpor para, no dizer de T.S. Eliot, dar à luz um texto "tão cheio de vida que deverá parecer tão presente para nós quanto o próprio presente"vii.

Faltava também encontrar uma editora que encampasse o projeto, mas essa foi a parte menos difícil. A Carambaia lançará este ano, espera-se, um volume único com "Espectros" ("Gengangere", 1881), "Um inimigo do povo" ("En folkefiende", 1882), "Hedda Gabler" ("Hedda Gabler", 1890) e "Solness, o construtor" ("Bygmester Solness", 1892) viii. As quatro foram cotejadas com: "Hedda Gabler" de Luiz Leite Vidal, encartada na revista "Dionysos" (ano e idioma original não creditados; possivelmente a partir do francês, circa 1960); "Um inimigo do povo", por Pedro Mantiqueira para a L\&PM (2003) a partir do francês (?); os dois volumes de "Seis Dramas" (Editora Escala, ano e local e idioma de partida não creditados, tradução de Vidal de Oliveira, possivelmente a mesma da Editora Globo, de 1983-5); "Eight Plays" de Eva La Gallienne (Modern Library College, NY, 1951); e as respectivas versões para o inglês disponíveis no sítio do projeto Gutenbergix ${ }^{\text {ix }}$.

Chamam a atenção de início, sobretudo nas traduções que se supõem indiretas dessa fortuna crítica, certas omissões de trechos inteiros. Marcações de cena, interjeições e mesmo situações ambíguas, que demandariam mais trabalho interpretativo do tradutor, foram suprimidas sem explicação - talvez em nome da clareza, talvez pelo texto de partida já ter sido mutilado, talvez pelo tradutor ter preferido abster-se de "subjugar a irracionalidade" da língua? Nesta tradução, me detive no inteiro teor dos originais.

Uma tradução não está imune a ideologias e idiossincrasias, algumas delas até já explicitadas aqui. Sendo assim, importa citar outras. Favoreceram-se construções e regências verbais arcaicas em detrimento de suas contrapartidas modernas, de modo a dar aos textos uma dicção mais antiga, um certo sabor machadiano, mesmo sob risco de dificultar-lhes um pouco a compreensão e fruição ou, pior, transformá-los num pastiche. Caberá ao leitor avaliar até que ponto é possível realizar este trabalho arqueológico e revisitar um discurso clássico numa cadência contemporânea sem desnaturar a ambos. Mas antes isto a perpetrar uma Hedda 
Gabler "de saco cheio dos 'bromances" do marido", por exemplox. O desabafo calhará bem numa eventual montagem aggiornata do drama; no livro impresso, melhor não.

Certos marcos nortearam uma jornada tradutória que lembra a de um Peer Gynt em busca do self. Na medida do possível, procurou-se: 1) evitar vocábulos cuja primeira datação em português seja posterior à publicação das obras; 2) não domesticar certas locuções e ater-se à exatidão de outras: "Jørgen" não vira "Jorge" nem "texugo" (Meles meles) se metamorfoseia noutro bicho, como ocorre em algumas das edições cotejadas; 3) empregar, com moderação, a segunda pessoa do singular, mas (quase) nunca o rebuscamento da segunda do plural.

Podeis ter certeza: estas duas últimas foram superadas sem intercorrências, mas a primeira baliza exigiu certa perícia. Senão, vejamos. Os convivas do inimigo do povo Tomas Stockmann bebem toddy, uma diluição de destilados ou vinho em água quente e açúcar, e continuarão a ingerir essa glória da mixologia escandinava do século XIX a menos que uma edição caridosa decida servir-lhes outra coisa. Mas onde seu sogro, o "velho texugo" Morten Kiil, queixa-se de ter sido tratado como um "cão vadio", o leitor atento estranhará ali a falta de um "vira-latas" ganindo. Vira-latas habitam o Brasil desde as caravelas, mas antes da década de 1950 eram só cachorros vadios - Nelson Rodrigues que o diga. E "rafeiros", só os há perambulando pelas ruas em Portugal. Paciência. Certos cães estranham-se uns aos outros.

É possível sacrificar um pouco da proximidade em nome da fidedignidade sem comprometer a fluência e o sentido? Julgue o leitor: "emocionante" (datação: 1939) caberia muito bem na tensão dramática entre a senhorita Hilde Wangel e o construtor Solness, mas foi preterido, assim como "empolgante" (datação: 1899), sempre que um dos dois se vê alvoroçado, animado, encorajado, enlevado, entusiasmado, excitado, extasiado, exultante, tenso ou vivaz - em suma, spandt (spent, na grafia vigente).

Tome-se, por outro exemplo, o budoar dos lares de "Espectros": fruentimmer (cf. o alemão Frauenzimmer) é o aposento e também a presença física, a companhia, a convivência com a recatada Regine Engstrand. A melhor correspondência para esta aglutinação está em "toque feminino", descartada em seguida por conferir, acreditei eu, um certo verniz contemporâneo a um vilarejo nos cafundós da Noruega do século XIX. O avanço dos retrocessos no Brasil de 2017 trataria de me desmentir.

Tudo isto posto, fica evidente que o resultado saberia a um certo lusitanismo, tamanha a distância, já mencionada, entre o que os brasileiros escrevemos e falamos ${ }^{\text {xi }}$. Pude também atestar o prazo de validade de uma tradução, sobretudo se o original é um clássico, exorcizando os avantesmas redivivos por Leite Vidal. 
Trata-se do uso castiço, mas não só. Chapéu, por exemplo, ainda se diz, mas já quase não se usa. Há costumes e hábitos que simplesmente caducaram: "faiança", "coroado de pâmpanos", "aí é que está o hic", "trajo" (substantivo), "punch", "portmanteau", "toilette de visita". O norvégien de antanho também era pródigo em galicismos.

Era natural também que muitas expressões no original adquirissem, com o passar do tempo, sentido diverso do que tinham há mais de cem anos - um convite irresistível ao erro. Assim é que rar, que em danês ainda significa "belo, distinto", em norueguês tornou-se um falso cognato: "estranho" (cf. extraño e bizarro em espanhol, p. ex.).

Como a ação de "Hedda Gabler" transcorre numa Oslo senhorial do final do XIX, procurei elevar o registro do discurso mesmo em situações coloquiais. $\mathrm{O}$ cargo do melífluo Brock foi traduzido por "juiz" (no original assessor, o magistrado de então). E certas nomenclaturas ganharam sua correspondência de época ou de lugar: "prefeito" por "intendente", "município" por "comarca", entre outros. Reparo agora que vou de encontro à opção de servir o toddy de alguns parágrafos atrás. Mas tradução é também contradição.

Sendo o norueguês uma língua germânica, mais sintética em relação às latinas, esbarra-se a todo momento em campos semânticos que não possuem a mesma equivalência. Para superá-los, tive que me haver com menos para dizer mais e ainda assim não incorrer em eventuais "equívocos por irreflexão", como alerta Schleiemacherrii.

Caso, por exemplo, de pligt (ou pliket no norueguês contemporâneo; cf. o alemão Pflicht): é "dever" como imperativo moral de foro íntimo ou "obrigação" sacrificial de conformar-se aos rígidos códigos sociais locais? Ambas as acepções, no mais das vezes esta última, convêm à resignação da esposa do construtor Solness. Aliás, "arquiteto" calha melhor ao bygmester (na grafia corrente: byggemester) que no passado projetava e executava as obras sem o aval de um engenheiro, mas receei contrariar a guilda da categoria ${ }^{\text {xiii. }}$ O "empreiteiro" que só põe a mão na massa para corromper governos certamente ele não era. E, bem, um "mestre de obras" não teria amealhado todo aquele patrimônio. Ergo, "construtor".

E o que dizer de uma viúva assombrada por espectros de outrora? O sentimento de angst que atormenta a senhora Helene Alving é aflição, agonia, ansiedade, angústia, aperto, medo, pavor (cf. o alemão Angst) ou uma resultante disso tudo? E quando a pobre Aline Solness avista o marido idoso arriscando a vida nas lonjuras de um andaime? Sem dúvida ambas padecem de enorme sofrimento (lidelse), que em rara vez posso ter convertido em "paixão" (lidenskap; cf. o alemão Leiden) 
Leidenschaft), seduzido pela tradição ibérica de apaixonar-se e sofrer com o mesmo estado d'alma. Melhor não faz o calvinismo escandinavo, ascético e pragmático, ao discernir uma coisa da outra?

Substantivos tipicamente noruegueses como trold (na grafia moderna, troll), designando tanto a personagem mítica quanto "magia" ou "feitiço" (cf. o inglês spell/charm) também mereceram tratamento à parte: no mais das vezes omitiu-se a figura do ente mitológico para evidenciar o seu efeito sobrenatural, isto é, o encantamento (cf. a acepção de troll no jargão da internet).

No que concerne à pontuação, manteve-se a minudência desejada pelo autor acompanhando-se a notação mais moderna, aliás adotada em todas as edições de cotejo. Travessões em final de frase deram lugar a reticências; sentenças encadeadas numa sequência de dois pontos foram desmembradas em duas ou mais.

Ante o dilema schleiemacheriano de "deixar em paz o autor ou o leitor", oscilei mais para lá que para cá. Não me aferrei a um cânone ou a um manual de estilo rígido e inflexível, apenas procurei observar a elocução do texto. Porém, ora por coerência, ora por simples gosto, ora por mera intuição, fiz escolhas que se distanciavam do original para lhe conferir fluência na chegada e alcançar o "ponto intermediário" que distingue cada tradução.

Concluo no mesmo tom confessional. Ao longo dos quatro meses que me consumiu o trabalho, pude perceber variações no grau de rarefação dos textos à medida que se desgrudam do real, assumem traços mais simbólicos e cedem espaço ao inconsciente. Apesar do registro mais culto, o aristocrático "Hedda Gabler" é "mais palpável" e, assim, "mais fácil" se comparado a "Solness, o construtor", em que o vanguardismo coloquial, o não-dito e as entrelinhas assomam e se impõem como obstáculos mais íngremes. Pelas mesmas razões, "Espectros" equipara-se a este último.

Se uma das características de um texto clássico é uma atemporalidade que desconhece todas as dificuldades aqui expostas, "O inimigo do povo" é certamente o exemplo mais pronto e acabado disso. A truculência cega das autoridades, a cidade que sucumbe ao poder do capital, o comportamento de manada dos seus habitantes, a sabujice de uma imprensa canalha, a execração pública de uma das poucas personagens lúcidas nesse processo... Por muitas vezes entrevi na tela do computador não o processador de texto, mas a página principal de algum portal de notícias no ano da graça de 2017.

Visionário como era - "marqueteiro", dirão até -, Henrik Ibsen devia saber que muito além das fronteiras da Noruega, nalgum país que sofresse de complexo de vira-latas - digo melhor, cão vadio -, onde fervilhassem as paixões e imperasse 
o medo, seu legado póstumo seguiria relevante. E nisso há de ter concluído que descortinar a psique humana como fez foi antes um dever que uma obrigação.

São Paulo, abril de 2017.

\section{Notas}

i Uma versão reduzida deste texto, igualmente inédita, foi apresentada à Casa Guilherme de Almeida como trabalho de conclusão da disciplina "História de Tradução" do Curso de Formação em Tradução Literária, ministrada pelo professor Érico Nogueira.

ii MENEZES, Tereza. "Ibsen e o novo sujeito da modernidade", Perspectiva, São Paulo, 2006.

iii O professor da USP Francis H. Aubert traduziu três peças de Ibsen ("A Dama do Mar", "Rosmersholm", "O Pato Selvagem") para as Edições Cotovia, de Portugal, em 2008.

iv Disponível em http://www.teses.usp.br/teses/disponiveis/8/8151/tde-01112007-141703/pt-br.php.

v SCHØLLHAMMER, K. E. (org.) “Henrik Ibsen no Brasil”. PUC/7 Letras, Rio de Janeiro, 2008.

vi O dinamarquês, por seu turno, conservou essas características, que dificultam sua compreensão oral e são motivo de troça por parte dos vizinhos escandinavos.

vii Citado em CAMPOS, Haroldo, "Metalinguagem e outras metas". Perspectiva, São Paulo, 1992.

viii Para a obra completa original em domínio público, ver a página na internet do Centro de Estudos sobre Ibsen da Universidade de Oslo: http://www.edd.uio.no/cocoon/ibsenarkiv01_02/forside.xhtml.

ix https://www.gutenberg.org/ebooks/author/861

x Digressão que não me escapou neste particular: somente a proverbial fleuma da sociedade escandinava para que Ibsen, com seu compêndio de transgressões para épater la bourgeoisie de então, não tenha tido destino semelhante ao de seu contemporâneo Oscar Wilde, a despeito dos escândalos que sucediam a cada estreia do norueguês no Teatro Nacional de Oslo.

xi Em relação ao português, as traduções inglesas do norueguês são menos afetadas neste aspecto, tanto pelo parentesco entre ambos estes idiomas como pela proximidade entre o inglês escrito e o falado.

xii "Dos diferentes métodos de traduzir", SCHLEIEMACHER, F. (trad. Mauri Furlan), in "Scientia Traductionis", n'. 9, 2011.

xiii A quem porventura achar que não é a sério: a empresa de um amigo jornalista foi notificada pelo cioso Conselho Regional de Engenharia e Arquitetura (Crea) por se intitular "Engenharia de Comunicação". 